\title{
Hyperthermia-induced radiosensitization in CHO wild-type, NHEJ repair mutant and HR repair mutant following proton and carbon-ion exposure
}

\author{
JUNKO MAEDA ${ }^{1}$, YOSHIHIRO FUJI ${ }^{2}$, HIROSHI FUJISAWA ${ }^{3}$, HIROKAZU HIRAKAWA ${ }^{4}$, IAN M. CARTWRIGHT ${ }^{1}$, \\ MITSURU UESAKA ${ }^{3}$, HISASHI KITAMURA ${ }^{5}$, AKIRA FUJIMORI ${ }^{4}$ and TAKAMITSU A. KATO ${ }^{1}$ \\ ${ }^{1}$ Department of Environmental and Radiological Health Sciences, Colorado State University, Fort Collins, CO 80523, USA; \\ ${ }^{2}$ Department of Radiological Sciences, Ibaraki Prefectural University of Health Sciences, Inashiki, Ibaraki 300-0394; \\ ${ }^{3}$ School of Engineering, The University of Tokyo, Tokyo 113-8656; ${ }^{4}$ Research Center for Charged Particle Therapy, \\ International Open Laboratory, and ${ }^{5}$ Research Development and Support Center, \\ National Institute of Radiological Sciences, Chiba 263-8555, Japan
}

Received October 29, 2014; Accepted August 17, 2015

DOI: $10.3892 / 01.2015 .3732$

\begin{abstract}
The DNA repair mechanisms involved in hyperthermia-induced radiosensitization with proton and carbon ion radiation exposure were investigated in the present study. In a previous study, Chinese hamster ovary $(\mathrm{CHO})$ cells were exposed to low linear energy transfer (LET) photon radiation. These cells can be sensitized by hyperthermia as a result of inhibition of homologous recombination (HR) repair. The present study used wild-type, non-homologous end joining (NHEJ) and HR repair-deficient $\mathrm{CHO}$ cells to define the contributions of each repair pathway to cellular lethality following hyperthermia-induced hadron radiation sensitization. The cells were exposed to ionizing radiation, followed by hyperthermia treatment $\left(42.5^{\circ} \mathrm{C}\right.$ for $\left.1 \mathrm{~h}\right)$. Hyperthermia-induced radiosensitization was determined by the colony formation assay and thermal enhancement ratio. HR repair-deficient cells exhibited no hyper-sensitization to X-rays, protons, or low and high LET carbon ions when combined with hyperthermia. Wild-type and NHEJ repair-deficient cells exhibited significant hyperthermia-induced sensitization to low LET photon and hadron radiation. Hyperthermia-induced sensitization to high LET carbon-ion radiation was less than at low LET radiation. Relative biological effectiveness (RBE) between radiation alone and radiation combined with hyperthermia cell groups was not significantly different in any of the cell lines, with the exception of wild-type cells exposed to high LET radiation, which exhibited a lower RBE in the combined group. The present study investigated additional cell lines to
\end{abstract}

Correspondence to: Dr Takamitsu A. Kato, Department of Environmental and Radiological Health Sciences, Colorado State University, 1618 Campus Delivery, Fort Collins, CO 80523, USA Email: takamitsu.kato@colostate.edu

Key words: hyperthermia, DNA repair, hadron radiation confirm the lower RBE observed in DNA repair-deficient cell lines. These findings suggested that hyperthermia-induced hyper-sensitization to hadron radiation is also dependent on inhibition of HR repair, as was observed with photon radiation in a previous study.

\section{Introduction}

Hyperthermia is known to sensitize mammalian cells to radiation treatment (1), and a better understanding of the molecular mechanism(s) involved in thermally induced radiosensitization may be beneficial for cancer treatments that involve concurrent radiotherapy and chemotherapy. Hyperthermia has four unique biological effects: i) cellular lethality with a break point of $\sim 42.5-43^{\circ} \mathrm{C}$, ii) hypersensitivity during late $\mathrm{S}$ phase (2), iii) thermotolerance (3), and iv) radiosensitization (4). Following hyperthermia, there are large initial changes in cellular metabolism and heat shock protein expression (5). Heat shock protein upregulation may explain the observed thermotolerance during hyperthermia, but does not provide an explanation for the remaining biological effects (6). A previous study defined the underlying mechanism of the classically accepted theory, that hyperthermia induces radiosensitization in low linear energy transfer (LET) photon radiation in a timeand temperature-dependent manner (7). The study utilized cell lines lacking homologous recombination (HR) repair pathways, and demonstrated that there was no radiosensitization when these cells were subjected to hyperthermia. Previous studies using wild-type cells have focused on the formation of Rad51 foci, which are involved in DNA repair and their presence correlates with cell survival following exposure to radiation. These studies have demonstrated a significant decrease, and even disappearance of radiation-induced Rad51 foci formation following hyperthermia $(7,8)$. These previous studies support the hypotheses that HR repair is suppressed by hyperthermia, and that Rad51 foci disruption or re-formation may be a fundamental molecular mechanism for sensitization to chemotherapeutic agents and ionizing radiation $(7,8)$. 
Hadron particle radiotherapy, such as proton and carbon-ion radiotherapy is one of the latest radiotherapy treatment strategies (9). There are 36 proton therapy facilities and six carbon ion facilities in operation worldwide, and $\sim 30$ more proton facilities and several other carbon ion facilities under construction or being planned. Proton and carbon-ion radiotherapy is known to have reduced latent effects in normal tissues and at least similar to greater tumor control, when compared to current photon radiation therapy (10). Proton and carbon-ion radiotherapy can be improved when combined with effective hyperthermia treatment (11-14).

A limited number of studies have investigated combined hyperthermia and particle radiation therapy. A previous study using human squamous cell carcinoma cells lines with $44^{\circ} \mathrm{C}$ for 10-20 min post irradiation hyperthermia demonstrated that accelerated carbon-ions with a LET of $\geq 100 \mathrm{keV} / \mu \mathrm{m}$ exhibited no hyperthermia-induced hypersensitization (11). Another previous study, using a Chinese Hamster Ovary cell line, $\mathrm{CHO}-\mathrm{SC} 1$ wild-type cells exposed to accelerated neon ions with a LET $<80 \mathrm{keV} / \mu$ m demonstrated successful hypersensitization using $41.5^{\circ} \mathrm{C}$ for $4 \mathrm{~h}$ post-irradiation treatment. The study revealed a similar thermal enhancement ratio (TER) for $42^{\circ} \mathrm{C}$ for $1.5 \mathrm{~h}$ treatment, which is as equitoxic as $41.5^{\circ} \mathrm{C}$ for $4 \mathrm{~h}$ (12). In another study, glioblastoma cell lines exposed to thermal neutron radiation were sensitized by treatment with hyperthermic conditions $\left(44^{\circ} \mathrm{C}\right.$ for $\left.15-40 \mathrm{~min}\right)$. However, no sensitization was observed when sufficient amount of boron was added, as neutron-captured boron releases lithium and $\alpha$ particle, which are very high LET radiation particles (13). The previous studies showed that decreased hyperthermia induced radiosensitization in high LET radiation. While the potential molecular mechanisms of hyperthermia-induced radiosensitivity are unclear, previous studies have confirmed that p53 is involved in hyperthermia-induced high LET radiosensitivity by regulating apoptosis $(11,14)$.

The aims of the present study were to elucidate the molecular mechanisms of hyperthermia-induced sensitization following exposure to hadron radiation, to clarify whether cells exposed to proton and carbon ion particles with different LET can be sensitized by hyperthermia, and to determine the repair mechanisms that may be responsible for this sensitization. To address these questions, wild-type Chinese hamster ovary (CHO) cells and two different DNA repair pathway-deficient cell lines were used.

\section{Materials and methods}

Cell culture. CHO wild-type (CHO 10B2) cells and the DNA repair-deficient $\mathrm{CHO}$ mutants, irs20 [DNA-dependent protein kinase catalytic subunit, (DNA-PKcs] (15) and xrs5 (Ku80) (16) were kindly supplied by Dr Joel Bedford of Colorado State University (Fort Collins, CO, USA). CHO wild-type (CHO AA8) cells and the DNA repair-deficient $\mathrm{CHO}$ mutants, V3 (DNA-PKcs) (17), 51D1 (Rad51D) and irs1SF (XRCC3) (18) were kindly supplied by Dr Larry Thompson of Lawrence Livermore National Laboratory (Livermore, CA, USA) (19). CHO cells were maintained in Alpha MEM (GE Healthcare Life Sciences, Logan, UT, USA) with 10\% fetal bovine serum (Sigma-Aldrich, St. Louis, MO, USA), antibiotics (Antibiotic-Antimycotic; Life Technologies,
Grand Island, NY, USA) and were cultured in incubators at $37^{\circ} \mathrm{C}$ with $5 \% \mathrm{CO}_{2}$ and humidity.

Hyperthermia and radiation conditions. X-ray irradiations were performed using a TITAN X-ray generator (Shimadzu Corp., Tokyo, Japan) using 5-mm Al and Cu filters at $200 \mathrm{kVp}$ and $20 \mathrm{~mA}$. The dose rate was $\sim 1 \mathrm{~Gy} / \mathrm{min}$ at room temperature. Hadron irradiations were conducted at the National Institute of Radiological Sciences (NIRS) in Chiba, Japan. Carbon and iron ions were accelerated to 290 and $500 \mathrm{MeV} / \mathrm{n}$, respectively, using the Heavy Ion Medical Accelerator in Chiba (HIMAC), and protons were accelerated to $70 \mathrm{MeV}$ using the NIRS-930 cyclotron. The dose rates for carbon ions and protons were set at $3 \mathrm{~Gy} / \mathrm{min}$. Monoenergetic $290 \mathrm{MeV} / \mathrm{n}$ carbon ions have a LET value of $13 \mathrm{keV} / \mu \mathrm{m}$ on entrance. Different LET values were achieved by varying the thickness of poly(methyl methacrylate) (20). Monoenergetic $70 \mathrm{MeV}$ protons have a LET value of $1 \mathrm{keV} / \mu \mathrm{m}$ on entrance. Monoenergetic $500 \mathrm{MeV} / \mathrm{n}$ iron ions have a LET value of $200 \mathrm{keV} / \mu \mathrm{m}$ on entrance. For hyperthermia experiments, tightly sealed cell culture containers were immersed in a pre-heated temperature-controlled water bath (Lauda, Delran, NJ, USA) at a temperature of $42.5^{\circ} \mathrm{C}$ for $1 \mathrm{~h}$. Hyperthermia treatment was carried out immediately following radiation exposure.

Cell survival colony formation assay. For the radiation and hyperthermia experiment, following exposure to radiation, the cells were kept at either $37^{\circ} \mathrm{C}$ or hyperthermia of $42.5^{\circ} \mathrm{C}$ for $1 \mathrm{~h}$, and subsequently trypsinized and plated to form colonies. For the radiation experiment with the additional cell lines, the cells were immediately plated following irradiation. Colonies were fixed and stained 7-10 days later using $100 \%$ ethanol, followed by $0.1 \%$ crystal violet. Macroscopic colonies containing $>50$ cells were marked as survivors (21). Cell survival curves were constructed from cell survival fraction data using Graphpad Prism 6 (GraphPad Software Inc., La Jolla, CA, USA) and a linear quadratic regression model. D10 values (radiation dose to achieve $10 \%$ cell survival) were determined, and the relative biological effectiveness (RBE) and thermal enhancement ratio (TER) were calculated from the D10 values $(7,20)$. X-ray was the standard radiation for RBE calculations.

Statistics. Experiments were performed at least three times and error bars indicated standard error of the means. Data analysis using the Student's t-test was performed with Prism 6. A statistically significant difference was defined as $\mathrm{P}<0.05$.

\section{Results}

Cell survival in response to hyperthermia combined with different types of radiation. In line with previous studies (7), cell survival curves demonstrated that hyperthermia treatment of $42.5^{\circ} \mathrm{C}$ for $1 \mathrm{~h}$ post irradiation, sensitized $\mathrm{CHO}$ wild-type cells and V3 cells but not 51D1 cells (Fig. 1). In low LET radiation including proton, $\mathrm{X}$-ray and carbon $13 \mathrm{keV} / \mu \mathrm{m}$, the cell survival curves of $\mathrm{CHO}$ wild-type and V3 [non-homologous end-joining (NHEJ) repair deficient] cells demonstrated significant and large differences between the control group (radiation only) and the combined group 
A
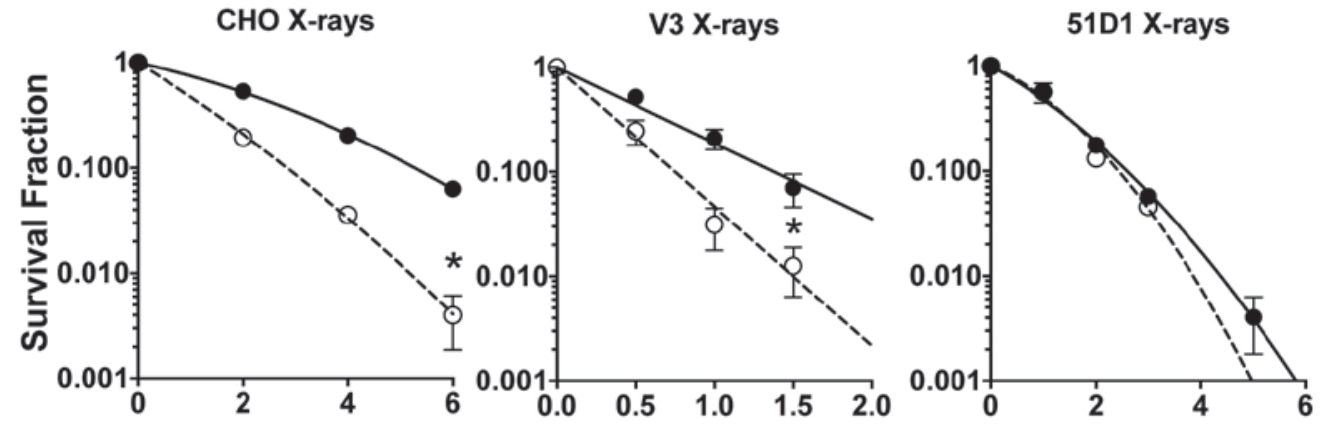

B
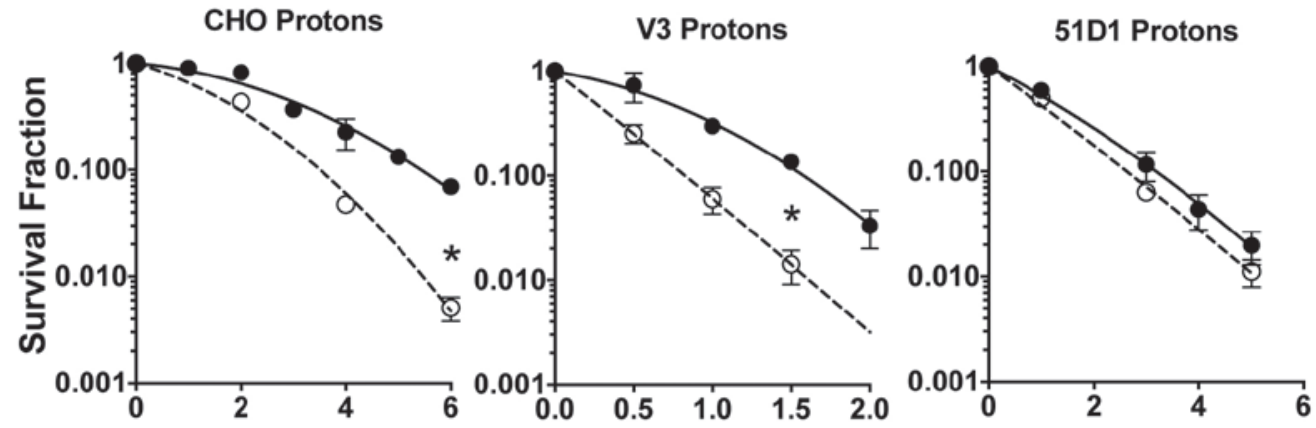

C
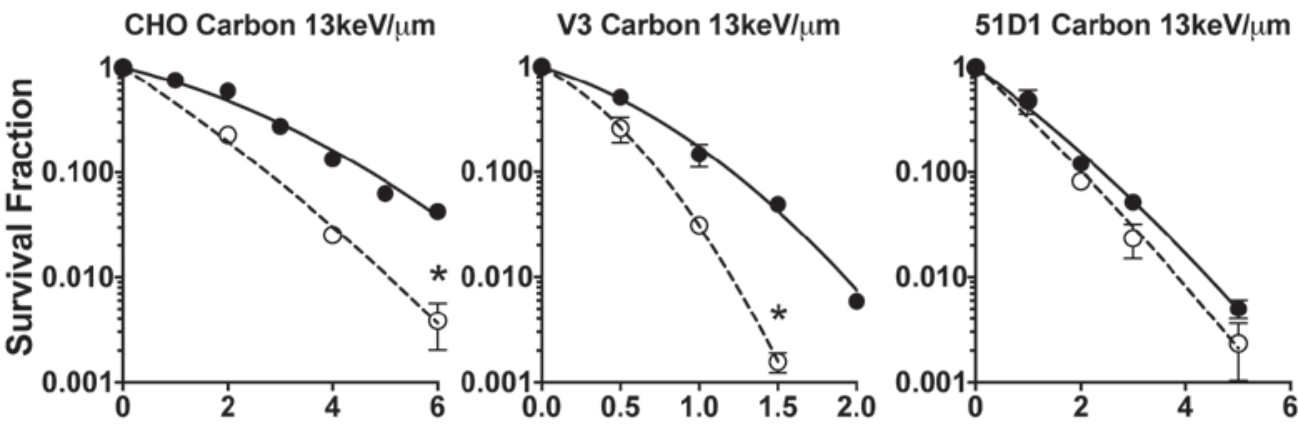

D
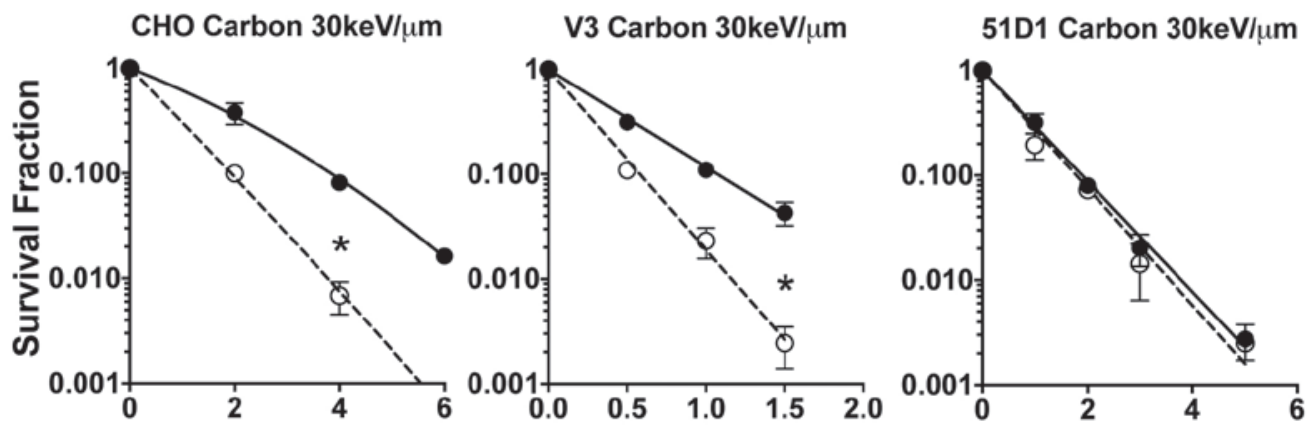

$\mathbf{E}$
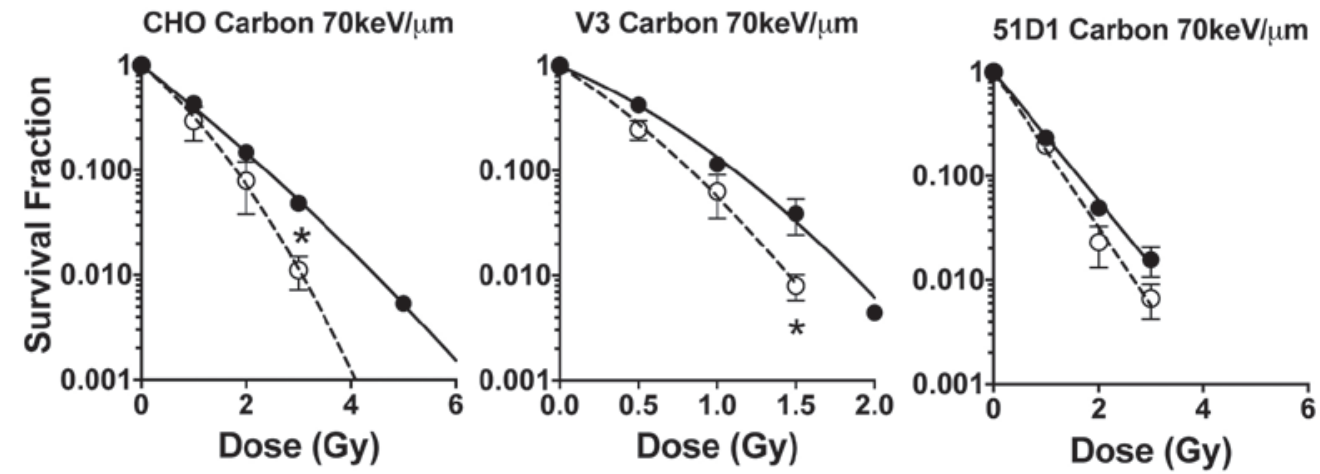

Figure 1. Cell survival curves for CHO wild-type, V3, and 51D1 cells exposed to (A) X-ray, (B) protons, (C) carbon $13 \mathrm{keV} / \mu \mathrm{m}$, (D) carbon $30 \mathrm{keV} / \mu \mathrm{m}$ or (E) carbon $70 \mathrm{keV} / \mu \mathrm{m}$. Solid lines are the control group (radiation alone). Dashed lines are the combined group (radiation with post-irradiation hyperthermia). Error bars are standard error of the mean values of at least three independent experiments. Trendlines were constructed using GraphPad Prism 6 with linear quadratic regression. ${ }^{*} \mathrm{P}<0.05$. $\mathrm{CHO}$, Chinese hamster ovary. 
A

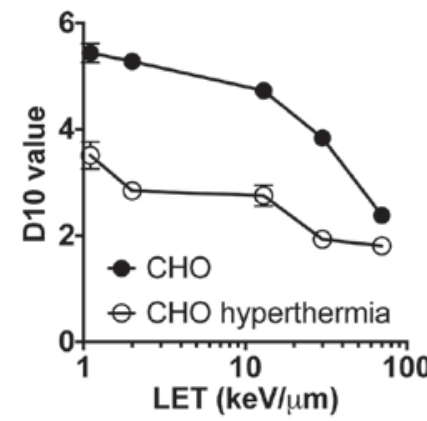

B

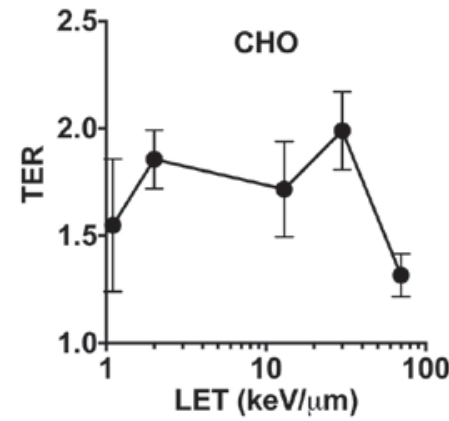

C



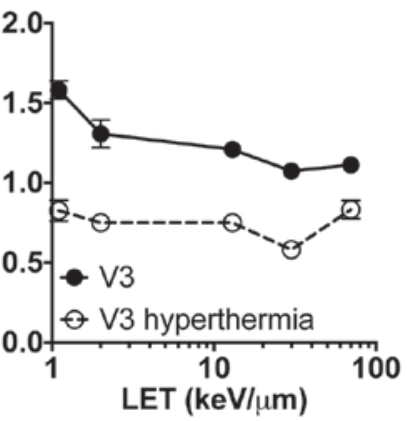
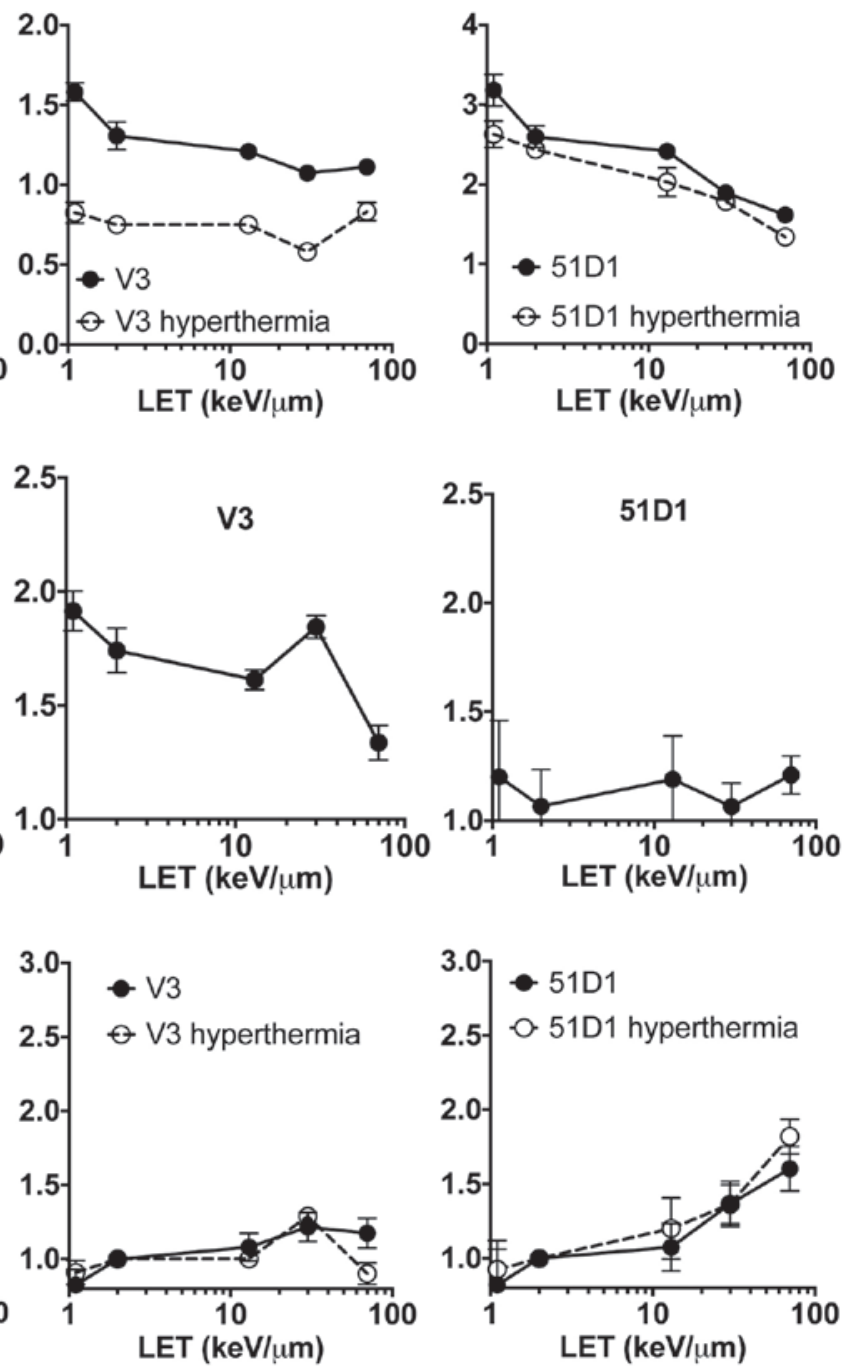

Figure 2. (A) D10 values of the control group (radiation alone, closed circles) and combined group (radiation combined with post-irradiation hyperthermia, open circles). (B) TER values of the control and combined groups. (C) RBE values of the control and combined groups. "P<0.05. CHO, Chinese hamster ovary; LET, linear energy transfer., RBE, relative biological effectiveness; TER, thermal enhancement ratio; D10, radiation dose to achieve $10 \%$ cell survival.

(radiation plus hyperthermia). However, the cells exposed to carbon 30 and $70 \mathrm{keV} / \mu \mathrm{m}$ LET showed significant but small differences in the cell survival curves between the control and combined groups. HR repair-deficient 51D1 cells exhibited no radiosensitization from the hyperthermia treatment in all the radiation conditions used in this study.

D10, RBE, and TER analysis. Analysis of the D10 values taken from the $\mathrm{CHO}$ wild-type and 51D1 cell survival data (Fig. 2A) revealed a clear trend in reduction of D10 values in the higher LET radiation for the control group (radiation only) and combined group (radiation plus hyperthermia). For the V3 cells, the control group had very small reductions in D10 values when LET increased. The combined group exhibited no observable changes in D10 values for the different values of LET. Comparison of the D10 values between the control and combined groups revealed the differences of each D10 were greatest in low LET radiation such as proton and X-rays, and at high LET radiation, these differences were smaller. Hyperthermia-induced radiosensitization in HR-deficient (51D1) cells (Fig. 1) resulted in no statistically significant differences in the D10 values of the control and combined groups. The D10 values were used to analyze the thermal sensitization. TER was obtained from D10 values of the control group of cells and the radiation plus hyperthermia (combined) group of cells (Fig. 2B). This analysis revealed that the data from the $\mathrm{CHO}$ wild-type and V3 cells followed a similar trend. In the LET range $1-30 \mathrm{keV} / \mu \mathrm{m}$, TER was calculated as 1.5-2.0. At the highest LET used in the present study, $70 \mathrm{keV} / \mu \mathrm{m}$, TER reduced to 1.3 . By contrast, there was no LET-dependent TER decrease for the HR repair mutant cells. The 51D1 group had a TER range of 1.0-1.2. Wild-type and NHEJ mutants have HR repair capacity, and the high TER values suggested that cells have a high HR repair capacity in low LET $<30 \mathrm{keV} / \mu \mathrm{m}$. RBE was also calculated from D10 values (Fig. 2C), and no statistically significant differences in RBE values were detected between control and hyperthermia-exposed cells among the three cell lines, with the exception of wild-type $\mathrm{CHO}$ cells exposed to carbon LET $70 \mathrm{keV} / \mu \mathrm{m}$ (high LET; P<0.05, t-test). The wild-type combined group RBE value at LET $70 \mathrm{keV} / \mu \mathrm{m}$ showed a significant reduction compared to the control group. This result suggested hyperthermia does not inhibit repair of the DNA damage produced by high LET radiation, or the DNA 
A
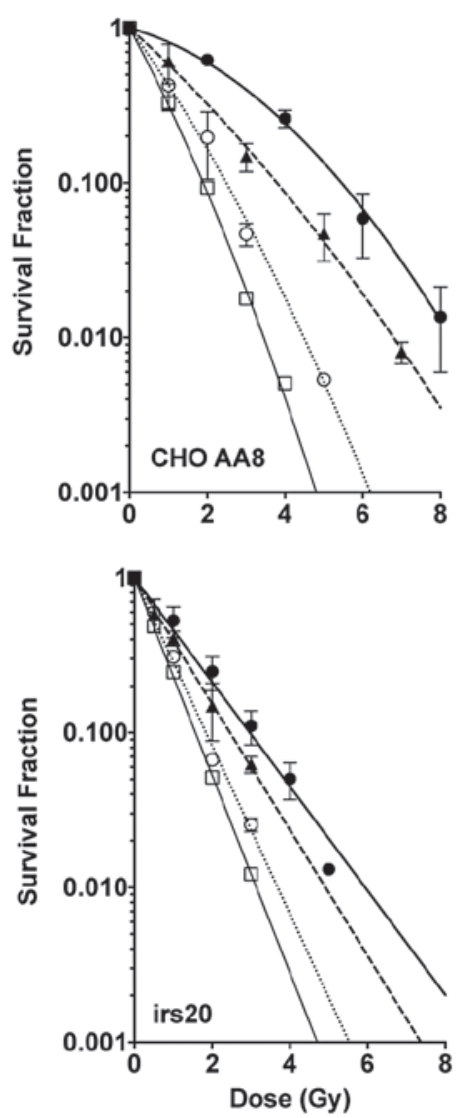
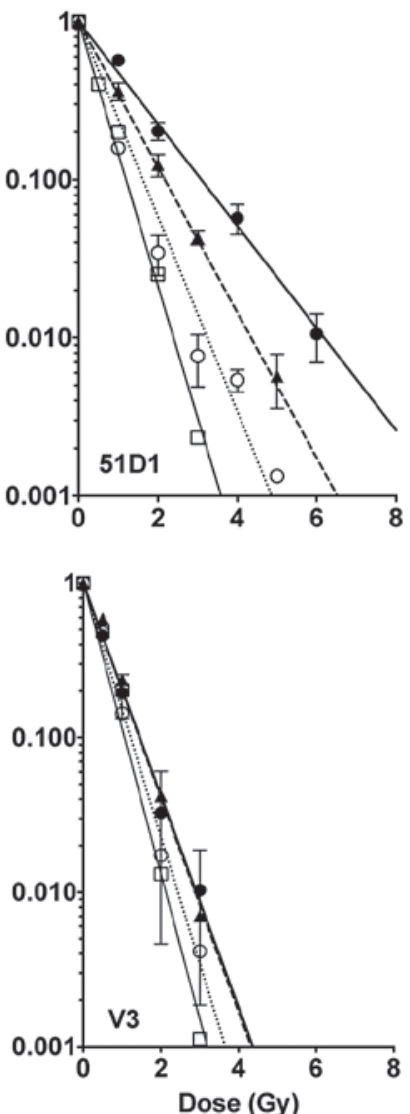
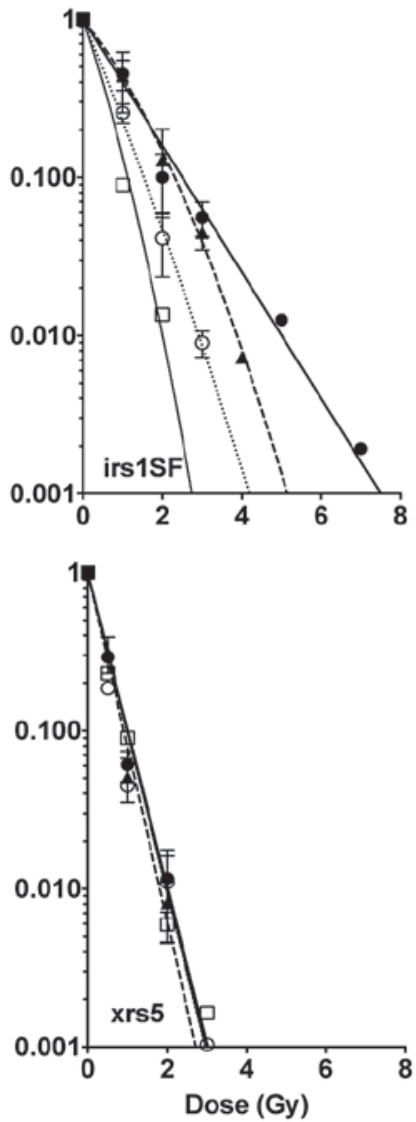

B

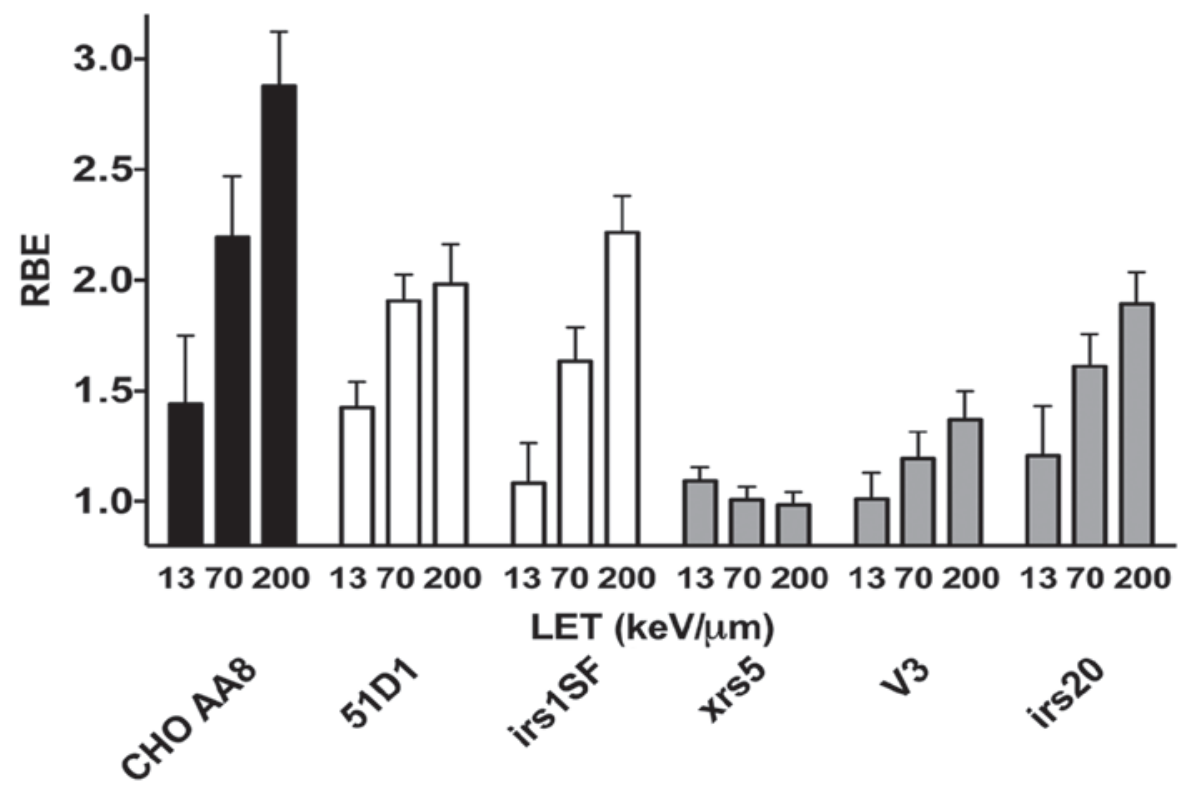

Figure 3. (A) Cell survival curves for CHO wild-type cells, NHEJ repair-deficient cells and HR repair-deficient cells. Closed circles indicate X-rays, closed triangles indicate carbon ion LET $13 \mathrm{keV} / \mu \mathrm{m}$, open circles indicate carbon ion LET $70 \mathrm{keV} / \mu \mathrm{m}$, and open squares indicate iron ion LET $200 \mathrm{keV} / \mu \mathrm{m}$. Error bars are the standard error of the mean values of at least three independent experiments. Lines were constructed using GraphPad Prism 6 with linear quadratic regression. (B) RBE values of CHO wild-type, xrs5, V3, irs20, 51D1, and irs1SF cells. CHO, chinese hamster ovary NHEJ, non-homologous end joining; HR, homologous recombination; LET, linear energy transfer; RBE, relative biological effectiveness.

repair pathway targeted by hyperthermia does not contribute to the repair of high LET radiation-induced DNA damage.

$R B E$ values of NHEJ repair mutants and HR repair mutants exposed to high LETradiation. Additional DNA repair-deficient
CHO mutants were used to further investigate the capacity of DNA repair following high LET radiation exposure (Fig. 3A). The radiosensitive NHEJ mutants, xrs5 cells did not exhibit a difference in RBE when LET was increased. The DNA-PKcs null mutant V3 showed a slight increase in RBE when LET 
was increased. By contrast, the intermediately radiosensitive irs20 cells exhibited a notable but intermediate RBE increase at LET 70 and $200 \mathrm{keV} / \mu \mathrm{m}$. Furthermore, 51D1 cells and the HR repair mutant irs1SF had a moderate increase in $\mathrm{RBE}$, but this change was not as large as that of the $\mathrm{CHO}$ wild-type cells (Fig. 3B).

\section{Discussion}

Hyperthermia treatment enhances radiation-induced cell death (1) and the present study set out to investigate the mechanisms underlying this effect. To the best of our knowledge, the present study is the first to use two different hadron radiations to directly compare the effects of proton and carbon ion radiation on cell survival following hyperthermia-induced radiosensitization. The results of the present study were in concordance with the results from previous studies that examined particle radiation and hyperthermia. Considering the results from the previous literature and the current study, it is clear that hyperthermia-induced radiosensitization is dependent on the LET of ionizing radiation. This applies to all of the previous studies and the present study, using thermal neutron, proton, helium, lithium, carbon, and neon ions (11-13).

The significantly large difference in RBE at the carbon LET $70 \mathrm{keV} / \mu \mathrm{m}$ between the control (radiation only) and radiation plus hyperthermia group may help to understand the induction and repair of DNA damage by high LET radiation. The results of the present study and previous studies indicate that the main target of hyperthermia is the HR repair pathway, as HR repair-deficient cells did not show any sensitization when combined with hyperthermia $(7,8)$. In cells where HR repair was active and properly functional, the cells were more sensitive to DNA damaging agents when exposed to hyperthermia than when no hyperthermia was used. We observed this hypersensitization even in V3 NHEJ mutant cells, which are particularly radiosensitive. Previous findings have demonstrated that NHEJ proteins, especially DNA-PKcs, are important for hyperthermia-induced radiosensitization (22-26). The hyperthermia condition caused hypersensitization in all types of radiation tested in the DNA-PKcs mutant V3 cell. Therefore, DNA-PKcs may be a target of hyperthermia-induced radiosensitization, however, its contribution to cellular lethality may be minor.

On comparison of the RBE at carbon LET $70 \mathrm{keV} / \mu \mathrm{m}$ in the different cell types, NHEJ mutants had the lowest RBE among the CHO cell lines. Thus, it is obvious that NHEJ is the primary repair pathway that counters DNA damage produced by any types of ionizing radiation. NHEJ mutant cells exhibited similar survival against low LET and high LET radiation (27). Loss of NHEJ prevents the effective repair of DNA damage produced by any type of ionizing radiation. By contrast, the RBE values of the HR mutants were similar to those of the $\mathrm{CHO}$ wild type, except at high LET radiation exposures. This result suggests that HR repair contributes to DNA repair, when DNA is damaged by low LET radiation (proton and low LET carbon ions), however, its contribution is minor for DNA damage caused by high LET radiation. Therefore, we conclude that HR repairs some DNA damage induced by high LET radiation, but its repair capacity is lower in high LET radiation-induced damage compared with low LET radiation.
High LET radiation is known to produce complex DNA damage that is difficult to repair. There are several previous studies concerning the limited contribution of HR repair to the damage induced by high LET radiation exposure $(28,29)$. If HR repair is more important in repairing high LET-induced DNA damage than low LET-induced damage, HR mutants should have larger RBE values when exposed to high LET radiation. The results of the present study nor our previous study (30) support this hypothesis.

Based on the results of the present and previous studies, it is clear that HR repair was responsible for the hyperthermia-induced radiosensitization for photon and hadron radiation. The lower TER in high LET radiation may be explained by the limited capacity of HR repair following high LET radiation exposure. However, there is a good possibility that alternative radiation damage-associated pathways to DNA double-strand break repair, can be inhibited or altered by hyperthermia and affect only certain types of ionizing radiation. Several good examples of such alternatives include heat shock proteins and p53 (11). ATM, the Fanconi Anemia signal pathway, and nucleotide excision repair pathway can be excluded as targets of hyperthermia based on previous studies $(31,32)$. The current study used photon radiation, two forms of hadron radiation, proton and carbon ion (low to high LET) radiation. Hyperthermia was unable to cause hypersensitivity in 51D1 cells exposed to hadron radiation and X-rays.

In conclusion, the results of the present study suggest that hyperthermia-induced radiosensitization for hadron radiation is dependent on HR inhibition, and these effects are significant for low LET hadron radiation. Synergistic cellular lethality effects may be expected from NHEJ inhibition.

\section{Acknowledgements}

The authors of the current study appreciate the technical support from the NIRS cyclotron and HIMAC. This study was partially funded by the Colorado State University start-up fund, the Dr Akiko Ueno Radiobiology research fund and the NIRS International Open Laboratory.

\section{References}

1. Dewey WC: Arrhenius relationships from the molecule and cell to the clinic. Int J Hyperther 25: 3-20, 2009.

2. Gerweck LE, Gillette EL and Dewey WC: Effect of heat and radiation on synchronous Chinese hamster cells: Killing and repair. Radiat Res 64: 611-623, 1975.

3. Holahan EV, Highfield DP, Holahan PK and Dewey WC: Hyperthermic killing and hyperthermic radiosensitization in Chinese hamster ovary cells: Effects of $\mathrm{pH}$ and thermal tolerance. Radiat Res 97: 108-131, 1984.

4. Dewey WC and Miller HH: Effect of temperature on x-ray induced cell lethality and chromosomal aberrations. Int J Radiat Biol Relat Stud Phys Chem Med 18: 91-93, 1970.

5. Lee YJ and Dewey WC: Induction of heat shock proteins in Chinese hamster ovary cells and development of thermotolerance by intermediate concentrations of puromycin. J Cell Physiol 132: 1-11, 1987.

6. Lee YJ and Dewey WC: Effect of cycloheximide or puromycin on induction of thermotolerance by heat in Chinese hamster ovary cells: Dose fractionation at 45.5 degrees C1. Cancer Res 47: 5960-5966, 1987.

7. Genet SC, Fujii Y, Maeda J, Kaneko M, Genet MD, Miyagawa K and Kato TA: Hyperthermia inhibits homologous recombination repair and sensitizes cells to ionizing radiation in a time- and temperature-dependent manner. J Cell Physiol 228: 1473-1481, 2013. 
8. Krawczyk PM, Eppink B, Essers J, Stap J, Rodermond H, Odijk H, Zelensky A, van Bree C, Stalpers LJ, Buist MR, et al: Mild hyperthermia inhibits homologous recombination, induces BRCA2 degradation, and sensitizes cancer cells to poly (ADP-ribose) polymerase-1 inhibition. Proc Natl Acad Sci USA 108: 9851-9856, 2011.

9. Kamada T, Tsujii H, Tsuji H, Yanagi T, Mizoe JE, Miyamoto T, Kato H, Yamada S, Morita S, Yoshikawa K, et al; Working Group for the Bone and Soft Tissue Sarcomas: Efficacy and safety of carbon ion radiotherapy in bone and soft tissue sarcomas. J Clin Oncol 20: 4466-4471, 2002.

10. Tsujii $\mathrm{H}$ and Kamada T: A review of update clinical results of carbon ion radiotherapy. Jpn J Clin Oncol 42: 670-685, 2012.

11. Takahashi A, Ohnishi K, Wang X, Kobayashi M, Matsumoto H, Tamamoto T, Aoki H, Furusawa Y, Yukawa O and Ohnishi T: The dependence of p53 on the radiation enhancement of thermosensitivity at different let. Int J Radiat Oncol Biol Phys 47: 489-494, 2000

12. Chang PY, Tobias CA and Blakely EA: Protein synthesis modulates the biological effectiveness of the combined action of hyperthermia and high-LET radiation. Radiat Res 129: 272-280, 1992 .

13. Kinashi Y, Masunaga SI, Suzuki M, Ono K and Ohnishi T: Hyperthermia enhances thermal-neutron-induced cell death of human glioblastoma cell lines at low concentrations of 10B. Int J Radiat Oncol Biol Phys 40: 1185-1192, 1998.

14. Takahashi A, Ohnishi K, Ota I, Asakawa I, Tamamoto T, Furusawa Y, Matsumoto $\mathrm{H}$ and Ohnishi T: p53-dependent thermal enhancement of cellular sensitivity in human squamous cell carcinomas in relation to LET. Int J Radiat Biol 77 : 1043-1051, 2001.

15. Stackhouse MA and Bedford JS: An ionizing radiation-sensitive mutant of CHO cells: Irs-20. I. Isolation and initial characterization. Radiat Res 136: 241-249, 1993.

16. Jeggo PA and Kemp LM: X-ray-sensitive mutants of Chinese hamster ovary cell line. Isolation and cross-sensitivity to other DNA-damaging agents. Mutat Res 112: 313-327, 1983.

17. Whitmore GF, Varghese AJ and Gulyas S: Cell cycle responses of two X-ray sensitive mutants defective in DNA repair. Int J Radiat Biol 56: 657-665, 1989.

18. Fuller LF and Painter RB: A Chinese hamster ovary cell line hypersensitive to ionizing radiation and deficient in repair replication. Mutat Res 193: 109-121, 1988.

19. Hinz JM, Tebbs RS, Wilson PF, Nham PB, Salazar EP, Nagasawa H, Urbin SS, Bedford JS and Thompson LH: Repression of mutagenesis by Rad51D-mediated homologous recombination. Nucleic Acids Res 34: 1358-1368, 2006.

20. Kato TA, Tsuda A, Uesaka M, Fujimori A, Kamada T, Tsujii H and Okayasu R: In vitro characterization of cells derived from chordoma cell line U-CH1 following treatment with X-rays, heavy ions and chemotherapeutic drugs. Radiat Oncol 6: $116,2011$.
21. Maeda J,RoybalEJ,Brents CA,Uesaka M,Aizawa Y and Kato TA: Natural and glucosyl flavonoids inhibit poly(ADP-ribose) polymerase activity and induce synthetic lethality in BRCA mutant cells. Oncol Rep 31: 551-556, 2014

22. Zeng ZC, Jiang GL, Wang GM, Tang ZY, Curran WJ and Iliakis G: DNA-PKcs subunits in radiosensitization by hyperthermia on hepatocellular carcinoma hepG2 cell line. World J Gastroenterol 8: 797-803, 2002.

23. Ihara M, Takeshita S, Okaichi K, Okumura Y and Ohnishi T: Heat exposure enhances radiosensitivity by depressing DNA-PK kinase activity during double strand break repair. Int J Hyperthermia 30: 102-109, 2014.

24. Tomita M: Involvement of DNA-PK and ATM in radiation- and heat-induced DNA damage recognition and apoptotic cell death. J Radiat Res (Tokyo) 51: 493-501, 2010.

25. Umeda N, Matsumoto Y, Yin HL, Tomita M, Enomoto A Morita A, Mizukoshi T, Sakai K, Hosoi Y and Suzuki N: Difference in the heat sensitivity of DNA-dependent protein kinase activity among mouse, hamster and human cells. Int J Radiat Biol 79: 671-680, 2003.

26. Woudstra EC, Konings AW, Jeggo PA and Kampinga HH: Role of DNA-PK subunits in radiosensitization by hyperthermia. Radiat Res 152: 214-218, 1999.

27. Weyrather WK, Ritter S, Scholz M and Kraft G: RBE for carbon track-segment irradiation in cell lines of differing repair capacity. Int J Radiat Biol 75: 1357-1364, 1999.

28. Olsson G, Czene S, Jenssen D and Harms-Ringdahl M: Induction of homologous recombination in the hprt gene of V79 Chinese hamster cells in response to low- and high-LET irradiation. Cytogenet Genome Res 104: 227-231, 2004

29. Zafar F, Seidler SB, Kronenberg A, Schild D and Wiese C: Homologous recombination contributes to the repair of DNA double-strand breaks induced by high-energy iron ions. Radiat Res 173: 27-39, 2010.

30. Genet SC, Maeda J, Fujisawa H, Yurkon CR, Fujii Y, Romero AM, Genik PC, Fujimori A, Kitamura H and Kato TA: Comparison of cellular lethality in DNA repair-proficient or -deficient cell lines resulting from exposure to $70 \mathrm{MeV} / \mathrm{n}$ protons or $290 \mathrm{MeV} / \mathrm{n}$ carbon ions. Oncol Rep 28: 1591-1596, 2012.

31. Mitchel RE, Smith BP, Wheatly N,Chan A, Child S and Paterson MC Sensitivity of hyperthermia-treated human cells to killing by ultraviolet or gamma radiation. Radiat Res 104: 234-241, 1985.

32. Mitchel RE, Chan A, Smith BP, Child SD and Paterson MC: The effects of hyperthermia and ionizing radiation in normal and ataxia telangiectasia human fibroblast lines. Radiat Res 99 627-635, 1984. 